EDUR • Educação em Revista. 2021;37:e25928

DOI: http://dx.doi.org/10.1590/0102-469825928

() (1) https://creativecommons.org/licenses/by/4.0/

ARTIGO

\title{
ELABORAÇÃO DE UM MATERIAL POTENCIALMENTE SIGNIFICATIVO: UMA ABORDAGEM HISTÓRICA PARA O ENSINO DE RAIZ QUADRADA
}

\author{
ANGELA MARIA VISGUEIRA CUNHA ${ }^{1}$ \\ ORCID: https://orcid.org/0000-0001-5747-4678 \\ JOSÉ ROBERTO DA SILVA ${ }^{2}$ \\ ORCID: https://orcid.org/0000-0003-2970-9702
}

\begin{abstract}
RESUMO: Este estudo, que propõe a elaboração de um material pedagógico sobre o ensino de raiz quadrada para ser vivenciado nos anos inicias do ensino fundamental, corresponde ao recorte de uma pesquisa realizada no mestrado em Educação da Universidade de Pernambuco. A História da Matemática e a Teoria da Aprendizagem Significativa, respectivamente, foram adotadas como aportes epistemológico e pedagógico. O percurso investigativo convergiu para a abordagem da pesquisa-ação e, no âmbito de suas fases, foram analisados os conhecimentos prévios de quatro professores sobre as Operações Fundamentais. Observou-se pouco domínio sobre os objetivos de matemática e os significados inerentes à adição, à subtração, à multiplicação e à divisão, propostos a mais de vinte anos pelos Parâmetros Curriculares Nacionais. Intencionando contribuir com a mudança na prática desses professores acerca do ensino de raiz quadrada, investiu-se na noção de quadrado perfeito e no método babilônico para o cálculo da raiz quadrada quando não se tem um quadrado perfeito, almejando que o material produzido possa ser qualificado como potencialmente significativo.
\end{abstract}

Palavras-chave: Anos iniciais do ensino fundamental, história da matemática; aprendizagem significativa, raiz quadrada.

\section{CREATION OF A POTENTIALLY MEANINGFUL MATERIAL: A HISTORICAL APPROACH TO SQUARE ROOT TEACHING}

\begin{abstract}
This study proposes the creation of a pedagogical material on square root teaching to be used in the early years of elementary school. It is part of a master research in Education at Universidade de Pernambuco. The History of Mathematics and the Theory of Meaningful Learning, respectively, were adopted as epistemological and pedagogical contributions. The investigative path converged towards the action research approach in which we analyzed the previous knowledge of four teachers on Fundamental Operations (OF). We observed insufficient expertise over mathematical goals and the inherent meanings of addition, subtraction, multiplication, and division proposed over twenty years ago by the National Curriculum Parameters. Intending to contribute to the change in practice of these teachers regarding
\end{abstract}

\footnotetext{
${ }^{1}$ Universidade Federal do Piauí (UFPI). Bom Jesus, PI, Brasil. < angelavisgueira@gmail.com>

${ }^{2}$ Universidade de Pernambuco (UPE). Nazaré da Mata, PE, Brasil. < jroberto.silva@upe.br> Educação em Revista|Belo Horizonte|v.37|e25928|2021
} 
square root teaching, we invested in the notion of a perfect square and in the Babylonian method to calculate the square root when there is not a perfect square, aiming that this material may be potentially meaningful.

Keywords: Early years of elementary school; history of mathematics; meaningful learning; square root.

\section{ELABORACIÓN DE UN MATERIAL POTENCIALMENTE SIGNIFICATIVO: UN ENFOQUE HISTÓRICO PARA LA ENSEÑANZA DE LA RAÍZ CUADRADA}

RESUMEN: Este estudio que propone la elaboración de un material pedagógico sobre la enseñanza de la raíz cuadrada que se experimentará en los primeros años de la Educación Primaria corresponde a una parte de una investigación realizada en la Maestría en Educación de la Universidad de Pernambuco. La Historia de las Matemáticas y la Teoría del Aprendizaje Significativo, respectivamente, se adoptaron como contribuciones epistemológicas y pedagógicas. La ruta de investigación convergió para el abordaje de investigación de acción y en el alcance de sus fases se analizó el conocimiento previo de cuatro docentes sobre Operaciones Fundamentales $(\mathrm{OF})$. Observamos poco conocimiento sobre los objetivos matemáticos y los significados inherentes a la suma, resta, multiplicación y división propuestos hace más de veinte años por los Parámetros Curriculares Nacionales (PCNs). Con la intención de contribuir al cambio en la práctica de estos maestros sobre la enseñanza de raíz cuadrada, se invirtió en la noción de cuadrado perfecto y en el método babilónico para calcular la raíz cuadrada cuando no tienes un cuadrado perfecto, con el objetivo de que el material producido pueda calificarse como potencialmente significativo.

Palabras clave: Escuela primaria; historia de las matemáticas; aprendizaje significativo; raíz cuadrada. 


\section{INTRODUÇÃO}

Alguns conteúdos matemáticos, no que se refere à realização das tarefas educativas dos professores e estudantes, são vistos como difíceis de serem vivenciados em sala de aula. Essas dificuldades podem ter origens diversas. Porém, prioritariamente, serão analisadas a partir das situações que as constituem em termos da abordagem didática e epistemológica do conhecimento específico em questão.

O objeto matemático central na discussão deste artigo é a raiz quadrada. $\mathrm{O}$ assunto, pouco explorado no ensino básico, tem valor considerável, pois a sua "extração" tanto despertou interesse quanto foi importante para a geometria e para álgebra, como lembra Carvalho (2010, p. 10): “[...] Essa operação tem nítida importância geométrica, pois permite calcular efetivamente o lado de um quadrado cuja área é conhecida. Além disso, muitos problemas que formulamos em nossa linguagem algébrica moderna conduzem ao cálculo de raízes quadradas".

Assim, intencionou-se sinalizar dificuldades pedagógicas sobre as operações fundamentais $(\mathrm{OFs})$ enfrentadas por professores e as suas possíveis implicações na aprendizagem desses conteúdos curriculares. A pesquisa em pauta centra-se na radiciação, enfocando a conceituação e o cálculo de raiz quadrada, e foi realizada no âmbito do mestrado profissional em educação da Universidade de Pernambuco (UPE), campus Mata Norte.

O artigo corresponde a um recorte dessa pesquisa de mestrado e trata da formulação de um material de ensino para ser vivenciado com professores do ensino fundamental dos anos iniciais (Pefais) com intuito de viabilizar uma aprendizagem significativa sobre raiz quadrada. $\mathrm{Na}$ elaboração desse material, levou-se em consideração as compreensões dos Pefais envolvidos na pesquisa acerca das ideias de quadrado perfeito e das operações de adição, multiplicação e potenciação como conhecimentos prévios.

O interesse por esse conteúdo ocorreu a partir da percepção de que, nos últimos dez anos, boa parte dos artigos da Bolema, Zetetiké e Dynamis sobre os anos iniciais do ensino fundamental tratam de temáticas mais gerais de educação, como currículo, avaliação, formação docente e discente, etc. Quanto aos temas específicos, o bloco de Tratamento da Informação detém o maior número de publicações, em que os artigos que abordam estatística e combinatória superam as publicações de probabilidade. Além disso, as abordagens sobre OFs centram-se em adição, subtração, multiplicação e divisão, raramente incluindo potenciação e radiciação.

A história da matemática (HM) foi adotada como tendência em educação matemática (EM), com intuito de embasar epistemologicamente a abordagem de um texto de apoio, material pedagógico, visando favorecer os processos ausubelianos de diferenciação progressiva e reconciliação integradora. Considerando o tipo de familiaridade que os Pefais já possuem sobre OFs, há expectativa de que o texto de apoio seja qualificado como material potencialmente significativo.

Em síntese, quanto ao cálculo para obtenção de raiz quadrada, historicamente fez-se uso de um método empregado na Babilônia antiga: “[...]. Esta denominación usualmente se extiende al conjunto de Estados situados entre el Tigris y Eufrates y que existieron en el período desde el año 2000 hasta el 200 a. n. e. Hasta nosotros han llegado alrededor de cien mil tablillas de arcilla con escritura cuneiforme. [...]" (Ríbinikov, 1991, p. 27).

Como lembra Mol (2013, p.23), "Os babilônicos usavam, para o cálculo da raiz quadrada, um método de aproximações sucessivas. [...]”. Esse procedimento era usado pelos babilônios antigos para obter a raiz de um valor numérico que não correspondia a um quadrado perfeito. Porém, o cálculo da raiz quadrada adotado neste artigo faz uso do método babilônico que se encontra no capítulo $\mathrm{V}$, “APOYOS. LAS FORMAS PARA AYUDAR”, de Bardera (2000, p. 196-197).

A sistematização textual deste artigo possui cinco seções, além desta introdução. $\mathrm{Na}$ primeira, há dois enfoques: o aporte teórico-epistemológico, respaldado na HM, e o pedagógico, na Teoria da Aprendizagem Significativa (TAS). Na seção seguinte, situam-se os aspectos metodológicos. $\mathrm{Na}$ terceira seção, encontra-se a análise das situações sobre OFs que os Pefais investigados utilizam nas suas práticas. $\mathrm{Na}$ quarta, apresenta-se o material sobre raiz quadrada. $\mathrm{Na}$ última seção, relata-se as considerações finais. 


\section{HM: CONSIDERAÇÕES SOBRE O ENSINO DE RAIZ QUADRADA}

As inter-relações entre a HM e a EM no Brasil foram iniciadas no Seminário Nacional de História da Matemática (SNHM), realizado no Recife na Universidade Federal Rural de Pernambuco, em 1995, e se fortaleceu com a instauração da HM como campo investigativo advinda do surgimento da Sociedade Brasileira de História da Matemática (SBHMat) em 1999. Nesse período, também surgiram os Parâmetros Curriculares Nacionais (PCNs), que, se comparados a posicionamentos de estudos mais recentes quanto às importâncias pedagógicas atribuídas a HM, apesar de incipientes, ainda hoje essa crítica envolvendo a sua forma de apresentação chega a ser pertinente.

Apresentada em várias propostas como um dos aspectos importantes da aprendizagem matemática, por propiciar compreensão mais ampla da trajetória dos conceitos e métodos dessa ciência, a História da Matemática também tem se transformado em assunto específico, um item a mais a ser incorporado ao rol de conteúdos, que muitas vezes não passa da apresentação de fatos ou biografias de matemáticos famosos (PCNs, 1997, p. 26).

Damazio (2011) reconhece a ausência de explicações sobre idealizações básicas, como um número inteiro elevado ao expoente zero ser igual a um. Também reconhece que, nos anos 1980, mesmo com poucas credenciais interpretativas, já havia interesse pela epistemologia de muitos conceitos matemáticos, entre eles a potenciação. Depois de recorrer a clássicos da HM, como Boyer (1996) e Ríbnikov (1987), sem êxito para apoiar as suas explicações, Damazio (op. cit.) faz opção por jogos pedagógicos na perspectiva histórico-cultural embasada em Vigotski (2001), com o propósito de aprofundar epistemologicamente a prática pedagógica.

Ainda acerca das contribuições decorrentes do uso da HM no ensino da matemática, podese apresentar a seguinte afirmação de Mendes e Chaquiam (2016, p. 17):

A história pode ser tomada como um aporte para esclarecimentos de cunho epistemológico e didático que poderão contribuir para o professor explicar e orientar a organização das matemáticas escolares. Nesse sentido as informações históricas poderão ser utilizadas para auxiliar o professor de matemática a melhorar o planejamento e a execução de suas explanações durante as aulas de matemática.

Essa citação remete a caminhos do uso da HM para melhorar o desempenho docente sobre a difusão do conhecimento matemático. No entanto, para que isso ocorra, o professor precisa estar devidamente preparado, não se trata apenas de ter feito algumas leituras sobre HM ou de saber replicar certas situações de ensino existentes acerca desse campo de estudo, disponibilizadas nas bibliotecas ou na internet.

Como lembram Gomes e Rodrigues (2014), nas aulas de matemática o aporte histórico pode favorecer a compreensão do fazer matemático, facilitando o entendimento de conceitos e as suas aplicações. Para Mendes, Fossa e Valdés (2006, p. 95),

O uso da História da Matemática como recurso didático é imprescindível, pois vai além de um mero elemento motivador nas aulas de Matemática, ou seja, constitui-se em um fator justificante para os porquês conceituais e teóricos da Matemática que devem ser aprendidos pelos estudantes.

Assim, nessas características há indícios de que o uso da HM pode enriquecer o conhecimento docente, melhorando a sua atuação em sala de aula. Nessa direção, Araman e Batista (2013, p. 04), ao dizerem que "A inserção de elementos históricos traz potencial benefício para a formação do professor de matemática, em diversos aspectos. [...]", corroboram com tais indícios ao preconizarem que a abordagem histórica conceitual permite conhecer evoluções, dificuldades de aquisição, bem como a sua importância temporal e, além desses enfoques, reconhecer outros conceitos que subsidiam a sua compreensão.

Nesse contexto, faz sentido imaginar que o uso adequado da HM, pressupondo o domínio de modos de lidar com o pensamento matemático em termos de competências, contempla as três formas seguintes, dentre as cinco apontadas por Niss (2010, p. 33), para desenvolver 
Habilidades para responder perguntas em Matemática e com a Matemática:

$\checkmark \quad$ Entender e lidar com as origens, os escopos e as limitações de determinados conceitos;

$\checkmark \quad$ Abstrair conceitos e generalizar resultados;

$\checkmark$ Distinguir os vários tipos de proposições matemáticas, como definições, teoremas, conjecturas e proposições concernentes a objetos únicos e casos particulares.

No uso de abordagens históricas voltadas para a raiz quadrada e, de certo modo, alinhadas com essa terceira forma de habilidades, vale a pena mencionar o trabalho de Carvalho (2010). Ele enfoca a extração de raiz quadrada recorrendo aos procedimentos mesopotâmicos: à aproximação de Hierão, que viveu na Grécia antiga; aos algoritmos indiano e chinês, este segundo, apesar das críticas sofridas, era tradicionalmente empregado na obtenção do cálculo da raiz quadrada no ensino fundamental; e a um método trazido por Isaac Newton, completamente distinto dos anteriores.

Para evidenciar a diferença entre o propósito educativo de Carvalho (2010) e o intencionado nesta pesquisa, optou-se por recorrer ao que Chevallard (1991) intitulou de saber, com as noções de matemáticas, paramatemáticas e protomatemáticas. Nessa perspectiva, a primeira noção remete ao conhecimento do conteúdo, e as duas últimas ao conhecimento pedagógico do conteúdo. Portanto, a proposta de Carvalho (2010) está mais voltada para o conhecimento do conteúdo.

Neste artigo, intenciona-se um ensino que oportunize a aquisição de raiz quadrada como um saber matemático com características inerentes a essas três noções anteriores. Em síntese, há três aspectos a serem explorados. Inicialmente, investe-se no significado do termo "raiz quadrada", não apenas etimologicamente, mas matematicamente. O Liber Abbaci ("O livro do ábaco" ou "O livro de cálculo”), de Leonardo de Pisa, publicado em 1202, segundo Gonçalves (2011, p. 83), relata que: "radixquadratum 16 aequalis 4", ou seja, "O lado do Quadrado de 16 é igual a 4". Dessa forma, fica claro que a palavra radix não significa raiz, e sim lado de um quadrado.

Após essa abordagem, outro aspecto também importante envolve o símbolo empregado para representar essa idealização. Em se tratando da origem acerca da sua representação simbólica (“ $\sqrt{ }$ ") ilustrada na Figura 1, esse símbolo está relacionado à abreviatura da palavra radix. Conforme relata Gonçalves (idem): "Quanto à origem do símbolo $\sqrt{ }$, o que aconteceu, de facto, foi que à medida que se foram fazendo cópias deste livro, a palavra radix foi sofrendo abreviações até chegar ao actual símbolo que não é mais do que um alongamento ou variação da letra r [...]”.

Figura 1 - Evolução simbólica (raiz quadrada).

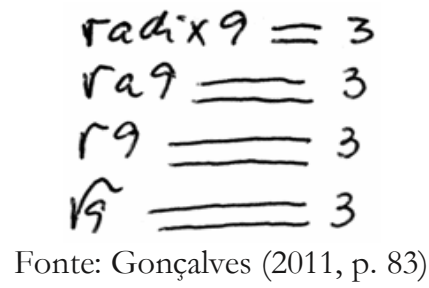

Assim, é possível identificar que houve uma evolução simplificada em relação à simbologia inicial que parte da representação escrita da própria palavra radix para a versão que se conhece atualmente, ou seja, a configuração de um alongamento da letra $\mathrm{r}$. Por fim, há um terceiro aspecto que compreende o cálculo da raiz quadrada cujo interesse decorreu da seguinte argumentação de Bardera (2000, p. 196): "Creo que no se ha dicho mucho todavía sobre la raíz quadrada, en referência a su algoritmo como en su papel de recurso didáctico".

\section{ASPECTOS TEÓRICOS E PEDAGÓGICOS QUE EMBASAM O ESTUDO}

O uso de teorias pedagógicas para embasar os estudos educacionais a partir dos anos 1980 do século passado aumentaram consideravelmente. Basta uma breve consulta aos anais do Encontro Nacional de Educação (SBEM) para constatar essa afirmação. Os interesses deste estudo foram 
pedagogicamente formulados a partir da teoria da aprendizagem significativa (TAS) ausubeliana, que, sucintamente, pode ser concebida, segundo Moreira (2016, p. 7), como

Um processo através do qual uma nova informação se relaciona, de maneira substantiva (não literal) e não-arbitrária, a um aspecto relevante da estrutura cognitiva do indivíduo. Neste processo a nova informação interage com uma estrutura de conhecimento específica, a qual Ausubel chama de "conceito subsunçor" ou, simplesmente "subsunçor", existente na estrutura cognitiva de quem aprende (grifos do original).

Moraes (2012) destaca que, com essa teoria, se aprende significativamente à medida que a nova informação passa a ter significado para o aprendiz. Contudo, a significação carece de subsídios de atributos pessoais. Essa consideração, dentre outras, encontra respaldo no valor atribuído ao conhecimento prévio do aprendiz nesse âmbito teórico, pois permite a construção de estruturas mentais que viabilizam desvendar outros conhecimentos, promovendo uma aprendizagem eficaz e prazerosa.

Em acréscimo, para realçar essa valorização acerca dos conhecimentos prévios basta observar a seguinte demarcação de Pozo (2005), conforme relata Ujiie et al. (2017, p. 61),

\begin{abstract}
As crianças realizam representações do mundo que as rodeia, consoante a sua própria maneira de ver o mundo e de ver a si próprio. Os conhecimentos prévios devem ser encarados como construções pessoais, que o professor tem o dever de procurar conhecer, compreender, e valorizar para decidir o que fazer e como fazer o seu ensino, ao longo do estudo de um tópico. Estes são construídos pelos estudantes a partir do nascimento e o acompanham também em sala de aula, onde os conceitos científicos são inseridos sistematicamente no processo de ensino e aprendizagem.
\end{abstract}

No marco ausubeliano, a estrutura cognitiva constitui-se de subsunçores inter-relacionados que estão hierarquicamente organizados e relacionados numa dinâmica segundo dois processos, a diferenciação progressiva e a reconciliação integradora. Esses processos encontram-se bem demarcados em Moreira (2011a). Para ele, "A diferenciação progressiva é o processo de atribuição de novos significados a um dado subsunçor (um conceito, uma proposição, por exemplo) resultante da sucessiva utilização desse subsunçor para dar significados a novos conhecimentos" (MOREIRA, 2011a, p. 20). Por sua vez, "A reconciliação integradora, ou integrativa, é um processo da dinâmica da estrutura cognitiva, simultâneo ao da diferenciação progressiva, que consiste em eliminar diferenças aparentes, resolver inconsistências, integrar significados, fazer superordenações" (p. 22).

Após a alusão a essas idealizações sobre a TAS, diante do interesse de querer saber se existe alguma condição básica para que ocorra efetivamente a aprendizagem significativa, o próprio Ausubel (2002, p. 25) destaca que isso "[...] Requiere tanto una actitud de aprendizaje significativa como la presentación de un material potencialmente significativo. [...]".

Sobre a segunda condição, Ausubel (idem) evidencia

1) que el propio material de aprendizaje se pueda relacionar de una manerano arbitraria(plausible, razonable y no aleatoria) y no literal con cualquier estructura cognitiva apropiada y pertinente (esto es, que posea un significado $<<$ lógico $>>$ );

y 2) que la estructura cognitiva de la persona concreta que aprendecontenga ideas de anclaje pertinentes con las que el nuevo material pueda relacionar.

Isso significa, conforme Moreira (2011a), que, antes da organização do conteúdo de ensino no ato da sistematização do material candidato a ser potencialmente significativo, é preciso identificar as ideias mais gerais, inclusivas, os conceitos estruturantes, as proposições-chave. Trata-se, intencionalmente, de mapear o conhecimento do aprendiz acerca do que se pretende ensinar, com intuito de trabalhar numa perspectiva de diferenciação e integração, ou seja, de descer e subir várias vezes nas hierarquias conceituais.

Além desse posicionamento, faz sentido trazer a advertência de Silva (2009) sobre a importância do processo de elaboração de material de ensino nas pesquisas com professores, em termos de implicações advindas do uso de enfoques teóricos, epistemológicos e pedagógicos na reflexão das suas práticas. Ele afirma que 
[...] la elaboración de propuestas didácticas derivadas de problemas enfrentados en el acto de la enseñanza, y que van desde la fragmentación de los contenidos presentados, pasando por equivocaciones y/o errores conceptuales, hasta una mala presentación de los contenidos por parte de los profesores, justifican la necesidad de una mejora [...] proponemos minimizar las dificultades en el acto de enseñanza, partiendo de la utilización de propuestas elaboradas por los propios profesores que buscan, entre otros factores, reducir al máximo la fragmentación, los errores y/o equivocaciones conceptuales, así como la deficiente exposición de los contenidos.

Há três considerações essenciais na elaboração de materiais educativos: que sejam logicamente significativos; que se reduza ao máximo a fragmentação entre os enfoques teóricos, epistemológicos, matemáticos e pedagógicos; e que se reduza também os erros ou equívocos conceituais. Associadas aos aspectos da HM para o ensino de raiz quadrada como aportes pedagógicos e epistemológicos, elas fundamentam o enfoque teórico desta pesquisa.

\section{ENFOQUE METODOLÓGICO}

Nas pesquisas em Educação - particularmente no que diz respeito ao ensino de ciências e matemática -, dentre os enfoques quantitativos e qualitativos (ou na combinação de ambos), tem-se observado uma preferência pelas abordagens metodológicas qualitativas. Essa consideração é compartilhada por pesquisadores da área, como Sampieri, Collado e Lucio (2010), André (2011) e Moreira (2011b).

$\mathrm{Na}$ intenção de apresentar uma visão global acerca do que pode ser concebido como pesquisa qualitativa, Moreira (2011b, p. 76) afirma que

O interesse central dessa pesquisa está em uma interpretação dos significados atribuído pelos sujeitos à suas ações em uma realidade socialmente construída, através de observação participativa, isto é, o pesquisador fica imerso no fenômeno de interesse. Os dados obtidos por meio dessa participação ativa são de natureza qualitativa e analisados de forma correspondente. As hipóteses são geradas durante o processo investigativo [...].

$\mathrm{Na}$ direção da intenção anunciada, sustentam Gerhardt e Silveira (2009, p. 31) que “A pesquisa qualitativa não se preocupa com representatividade numérica, mas sim com aprofundamento da compreensão de um grupo social, de uma organização, etc.” E, no que diz respeito à postura do pesquisador, o extrato de Deslauriers (1991), trazido por Gerhardt \& Silveira (2009, p. 32), evidencia que,

Na pesquisa qualitativa, o cientista é ao mesmo tempo o sujeito e o objeto de suas pesquisas. $\mathrm{O}$ desenvolvimento da pesquisa é imprevisível. O conhecimento do pesquisador é parcial e limitado. O objetivo da amostra é de produzir informações aprofundadas e ilustrativas: seja ela pequena ou grande, o que importa é que ela seja capaz de produzir novas informações.

Há outros aspectos a serem destacados em relação ao enfoque qualitativo. No que se refere às formas metodológicas - se comparadas a outras formas de abordagem -, a etnografia, o estudo de caso e a pesquisa-ação ocupam lugar de destaque nas pesquisas em educação. Para Eliot (1993, p. 67), "O objetivo fundamental da pesquisa-ação consiste em melhorar a prática em vez de gerar conhecimentos. A produção e utilização do conhecimento se subordinam a este objetivo e estão condicionadas por ele. [...]".

Dionne (2007), por sua vez, define a pesquisa-ação como metodologia de ação, em forma de processo de enquadramento da ação, e ilustra a sua visão por meio do processo de resolução de problemas, processo que compreende as seguintes etapas: identificação da situação, projeção de soluções, implementação de soluções e avaliação do procedimento.

Em síntese, propõe-se: identificar a forma como os Pefais promovem o ensino de raiz quadrada; formular hipóteses, recorrendo à planificação de atividades para melhorar as ações diagnosticadas; executar essas atividades; e avaliar os resultados obtidos. Esses intentos estão coesos com 
as etapas da pesquisa-ação apontadas por Dionne (op. cit.). Portanto, o enfoque metodológico desta pesquisa corresponde à pesquisa-ação.

\section{Os participantes e o lócus da pesquisa}

A pesquisa foi realizada em Sigefredo Pacheco, município brasileiro do estado do Piauí com população de 14.456 habitantes, de acordo com o último senso demográfico realizado pelo Instituto Brasileiro de Geografia e Estatística (IBGE), e contou com a participação de cinco professores - um homem e quatro mulheres. O professor tem 22 de idade e um ano de magistério. Quanto às mulheres, em ordem crescente, as idades são 26, 34, 37 e 45 anos e os respectivos tempos de magistério são dois, 12, 14 e 21 anos. Como o professor A não havia ainda sido contratado, ele não consta das análises do relatório.

\section{Procedimentos adotados}

O estudo possui quatro fases. Na primeira, visa-se à identificação de problemas iniciais que possam orientar a melhora do desempenho da prática dos Pefais a partir da forma como conduzem particularmente o ensino de raiz quadrada. Na segunda, embasa-se epistemologicamente os professores sobre HM, TAS e aritmética com autonomia para elaborarem planos de ação docente mais consistentes e atividades de ensino que oportunizem uma aprendizagem significativa, com o intuito de contemplar as hipóteses que solucionem os problemas iniciais levantados. A terceira envolve a elaboração de atividades embasadas nos três enfoques evidenciados na etapa anterior para serem vivenciadas junto com os docentes, a fim de implementar o novo plano e as atividades formuladas por meio de intervenção. $\mathrm{Na}$ quarta, realiza-se a avaliação final do processo, visando demarcar e difundir os resultados obtidos para serem apreciados em termos de viabilidade ou necessidade de reativação do processo.

\section{Apresentação dos critérios adotados nas análises}

Formularam-se os critérios para viabilizar a análise das situações trazidas pelos quatro Pefais nas fases I, de identificação, e II, de projetação, no âmbito da pesquisa-ação, identificando se há compatibilidade entre a potencialidade das situações sobre OFs que utilizam nas suas aulas dos anos iniciais do ensino fundamental (Aief) e o que alegam a esse respeito. A potencialidade será observada segundo dois enfoques, 16 objetivos e oito significados, quatro para adição/subtração e quatro para multiplicação/divisão, todos oriundos dos PCNs (1997).

Para identificar-se as (in)compatibilidades entre o que dizem os professores - relativamente às OFs nos Aief - e as suas práticas educativas, foram estabelecidas as quatro categorias seguintes:

1. não relacionada (NR), quando não há associação alguma entre a justificativa apresentada pelo professor e qualquer um dos objetivos/significados relacionados à situação por ele trazida;

2. relação incompatível (RI), quando a justificativa apresentada relaciona-se de forma incipiente com um dos objetivos/significados, mas não corresponde aos da situação em questão;

3. relação parcialmente compatível (RPC), quando a justificativa explicitada alude a alguns aspectos dos objetivos/significados, mostrando certa compatibilidade com os da situação indicada;

4. relação compatível (RC), quando a justificativa apresentada relaciona-se adequadamente com os objetivos/significados, correspondendo aos da situação trazida.

\section{ANÁLISE DAS SITUAÇÕES UTILIZADAS SOBRE OFs}

Estima-se, neste tópico, fazer a correlação entre os 16 objetivos e os quatro significados sobre adição/subtração dos PCNs (1997) para identificar se as situações de ensino e as justificativas de escolhas apresentadas pelos Pefais estão respaldadas por esses critérios. A avaliação decorre da hipótese inerente a essa inquietação vivenciada na identificação das situações iniciais e na análise dos resultados correspondentes às fases I e IV da pesquisa-ação. Os Pefais apresentaram situações para todas as 
operações fundamentais, porém, devido às necessidades de limitação textual do artigo, pressupõe-se que as situações do professor D sobre as operações de multiplicação (Figura 2) e divisão (Figura 3), que são apresentadas posteriormente, servem para aludir ao percurso investigativo.

\section{Categorização da situação de multiplicação do professor D na fase I}

Figura 2 - Situação sobre a operação de multiplicação escolhida pelo professor D.

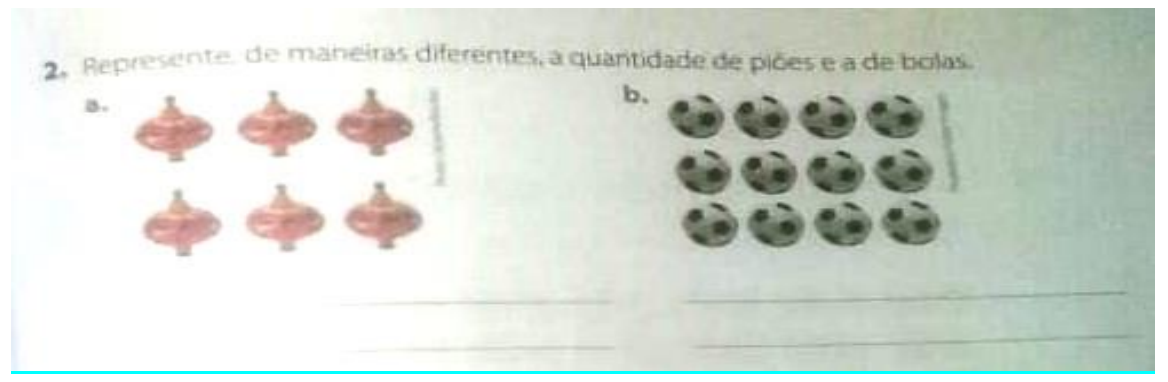

Fonte: Bigode (2005, p. 92)

A situação de multiplicação apresentada por esse professor, quanto ao significado, remete ao terceiro grupo dos PCNs (1997, p. 110): “[...] as situações associadas à configuração retangular”. No que diz respeito aos objetivos de matemática, essa situação é melhor associada ao quarto objetivo trazido para o segundo ciclo apresentado nos PCNs (op. cit, p. 80): "Resolver problemas, consolidando alguns significados das operações fundamentais e construindo novos, em situações que envolvam números naturais e, em alguns casos, racionais".

O extrato seguinte foi obtido da transcrição da entrevista da pesquisadora com o professor D:

PESQUISADORA: E, dentre as questões de multiplicação que você conhece, por que fez opção por essa situação?

PROFESSOR D: Ela pede que o aluno [...] ele arme essas operações. E acho que isso é importante pra ele saber, também, além de saber responder, saber fazer também.

PESQUISADORA: Mas [...] o que você acha que ela traz sobre a multiplicação para o seu aluno aprender?

PROFESSOR D: Ele pode perceber [...] duas formas diferentes nesse caso aí, porque dá pra fazer 2 vezes 3 e também 3 vezes 2, que, no caso, o resultado vai dar o mesmo. E representar a quantidade lá de maneira diferente.

Essa exposição dialógica do professor D aproxima-se do objetivo 5, mas, como a situação trazida por ele está voltada para o objetivo 4, essa sua justificativa categoriza-se como RI. O significado inerente a esse diálogo associa-se implicitamente à configuração retangular (3), mas, como a situação trazida pelo professor D está voltada para a ideia de combinatória (4), também foi categorizada como RI.

No entanto, nessa mesma exposição que envolve a justificativa do professor $\mathrm{D}$, ainda quanto ao significado, é importante destacar que ele não descreve nada que possa revelar o reconhecimento da existência de "[...] ambiguidade em relação à comutatividade da multiplicação. Embora, matematicamente, $\mathrm{a} \times \mathrm{b}=\mathrm{b} \times \mathrm{a}$, no contexto de situações como a que foi analisada (dos comprimidos) isso não ocorre" (PCNs, 1997, p. 109).

\section{Categorização da situação de multiplicação do professor D na fase II}

A situação em questão, indicada pelo professor D, continua a mesma. Logo, tanto o objetivo 4 como a configuração retangular (3) são mantidos. Apenas agora ele já passou pelo processo de intervenção. 
D:

O extrato seguinte foi obtido da transcrição da entrevista da pesquisadora com o professor

PESQUISADORA: Você acha que mudou alguma coisa em relação à sua ideia inicial sobre o que os seus alunos aprenderiam de multiplicação com essa situação?

PROFESSOR D: Aqui, no caso, dá pro aluno desenvolver tanto com adição como com multiplicação. E aí, depois, ainda dá pra mostrar pra ele como a adição e a multiplicação estão relacionadas, que, no caso, a multiplicação é uma forma pra facilitar quando se tem os números maiores.

Nesse extrato, observa-se a associação com o objetivo 4, que, por corresponder ao mesmo objetivo da situação trazida por ele, foi categorizada como RPC. No caso da associação do significado da situação trazida pelo professor D - a configuração retangular (3) -, esse extrato não esboça relação alguma com nenhum dos quatro significados (PCNs, 1997), por isso foi identificada como NR.

\section{Categorização da situação de divisão do professor D na fase I}

Figura 3 - Situação sobre a operação de divisão escolhida pelo professor D.

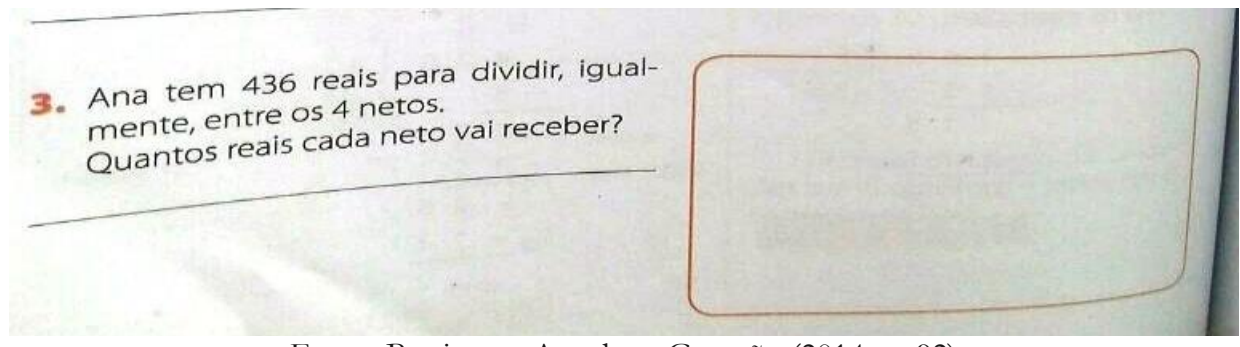

Fonte: Bonjorno, Azenha e Gusmão (2014, p. 92)

Essa situação selecionada pelo professor D para divisão, em termos de propósito educativo, segundo os objetivos existentes nos PCNs (1997, p. 81), aproxima-se do objetivo 5: "Ampliar procedimentos de cálculo - mental, escrito, exato, aproximado - pelo conhecimento de regularidade dos fatos fundamentais, de propriedades das operações e pela antecipação e verificação de resultados". No caso da construção de significados, essa situação remete à ideia de proporcionalidade (2), declarada no segundo grupo de significados nos PCNs (op. cit., p 110): "Num segundo grupo, estão as situações associadas à comparação entre razões, que, portanto, envolvem a idéia de proporcionalidade".

O extrato seguinte foi obtido da transcrição da entrevista da pesquisadora com o professor D:

PESQUISADORA: Em que esta situação pode contribuir para a aprendizagem dos seus alunos? PROFESSOR D: Eu acho que eles também podem aprender a fazer outros cálculos, resolver outros probleminhas que aparecem no dia a dia deles.

Essa justificativa do professor D pode ser associada ao objetivo 6. No entanto, como a situação trazida por ele está associada ao objetivo 04 , a categorização correspondente foi RI. Como não se observa nenhuma associação dessa fala do professor D com algum dos quatro significados já citados na fase II sobre a situação de multiplicação, a categorização atribuída a tal associação foi NR.

\section{Categorização da situação de divisão do professor D na fase II}

Como se trata da mesma situação indicada pelo professor D - mas depois da intervenção , tanto o objetivo 5 como a ideia de proporcionalidade, em termos de significado, permanecem os mesmos.

O extrato seguinte apresenta a indagação feita ao professor D e a sua resposta:

PESQUISADORA: Em termos da aprendizagem de divisão, retomando a situação que você escolheu, que tipo de contribuição ela pode trazer para essa aprendizagem?

Educação em Revista|Belo Horizonte|v.37|e25928|2021 
PROFESSOR D: Primeiramente, é um caso que envolve dinheiro, que é algo da vivência dos meninos, né? Então, quando é uma coisa assim, eles já se interessam mais. Depois, dá pra trabalhar a questão da operação em si mesma, partir pra divisão e, após isso, dá pra eles fazerem a confirmação utilizando a multiplicação. Então é uma questão que dá pra trabalhar as inversas.

Nessa exposição, observa-se, na primeira parte, certa associação com o objetivo 15 dos PCNs (1997, p. 82): "Demonstrar interesse para investigar, explorar e interpretar, em diferentes contextos do cotidiano e de outras áreas do conhecimento, os conceitos e procedimentos matemáticos abordados neste ciclo". Na segunda parte, há associação entre essa justificativa apresentada e o objetivo correspondente (5), o que a permite categorizar como RC. Em relação à associação dessa fala com o significado da situação, por não existir no extrato nada relacionado à ideia de proporcionalidade, foi categorizada como NR.

\section{Análise sobre os objetivos de adição/subtração}

FASE I: as situações sobre a adição referidas pelos professores C e D correspondem aos objetivos 3 e 5, mas as suas justificativas aproximam-se do objetivo 16 e, por isso, foram categorizadas como RI. No caso dos professores B e E, as situações apresentadas estão associadas aos objetivos 6 e 5. Destaca-se que, enquanto a justificativa do professor B foi associada ao objetivo 16 e categorizada como $\mathrm{RI}$, a do professor $\mathrm{E}$ foi associada ao objetivo 5 e categorizada como RPC. Na subtração, as situações mencionadas pelos professores B, C, D e E correspondem, respectivamente, aos objetivos 3, 2, 4 e 1, ao passo que as justificativas apresentadas associam-se aos objetivos 5, 3, 16, 5. Isso confere a elas a categorização de RI.

FASE II: a situação de adição relatada pelo professor $C$ foi associada ao objetivo 3 e caracterizada como RPC. Quanto à fala do professor B, foi associada ao objetivo 6, e a dos professores $\mathrm{D}$ e E, ao objetivo 5, cujas justificativas, por voltarem-se para os objetivos 16, 4 e 1, foram situadas como RI. Quanto à situação de subtração, as justificativas dos professores D e E, por estarem associadas aos objetivos 4 e 1, caracterizam-se como RPC. As justificativas dos professores B e C, por associarem-se aos objetivos 5 e 3, classificam-se como RI.

\section{Análise em relação aos significados}

FASE I: na adição, a ideia de juntar (1) figura no item (a), nas situações expostas pelos professores B e D e na situação do professor E, enquanto que as ideias de comparação (3) e mais de uma transformação (4) foram associações, nessa ordem, com o item (b,) na situação do professor D e na situação do professor C, todas classificadas como NR. Na subtração, o significado de juntar (1) figura na situação do professor E, o de transformação (2) nas situações dos professores B, no item (a), e C, no item (b), o de comparação (3) na situação do professor C, no item (c), e o de mais de uma transformação (4) na situação do professor D. Todas essas situações para NR.

FASE II: na adição, o significado de juntar (1), relacionado à justificativa do professor B no item (a), evoluiu de NR para RPC. Porém, quanto às justificativas do professor D, no item (a), e do professor E permaneceram como NR. Quanto ao significado de comparação (3), da justificativa do professor D no item (b), e o de mais de uma transformação (4), do professor C, também se mantiveram como NR. Na subtração, os significados de juntar (1), transformação (2), comparação (3) e mais de uma transformação (4), correspondentes às justificativas do professor $\mathrm{E}$, dos professores $\mathrm{B}$ e C, nos itens (a) e (b), do professor C, no item (c), e do professor D, de forma análoga ao ocorrido na fase I, a categoria de NR prevaleceu.

\section{Comentário sobre a análise em relação aos objetivos/significados}

$\mathrm{Na}$ adição, apenas o professor $\mathrm{C}$ evoluiu da categoria $\mathrm{RI}$, na fase I, para a categoria RPC, na fase II. Contudo, na subtração, observaram-se duas evoluções análogas: os professores D e E passam, obviamente, da categoria RI, na fase I, para a categoria RPC, na fase II. Na subtração, em relação aos significados inerentes a essas situações que devem ser vivenciadas, na adição/subtração, ficou explícito 
que os Pefais não conseguem explorá-los nas suas práticas. Por fim, identificou-se que os Pefais têm dificuldades de vivenciar nas suas aulas sobre adição/subtração os dezesseis objetivos e os quatro significados estabelecidos nos PCNs (1997).

\section{Análise sobre os objetivos de multiplicação/divisão}

FASE I: as situações de multiplicação apresentadas pelos professores $\mathrm{B}$ e $\mathrm{E}$ foram associadas aos objetivos 3 e 6 , mas, como as suas justificativas corresponderam aos objetivos 2 e 16, foram classificadas como RI. A situação apresentada pelo professor C associa-se ao objetivo 5 e a do professor $\mathrm{D}$ ao objetivo 4. Ambos tiveram as suas respectivas justificativas associadas aos objetivos 1 e 4, o que fez com que thes fosse conferidas as categorias de RI e RPC. No caso da divisão, as situações postas pelos professores B, C, D e E, associadas, nesta ordem, aos objetivos $6,16,5$ e 1, cujas justificativas correlatas estiveram associadas aos objetivos 3, 2, 5 e 16, foram categorizadas como RI, RI, RPC e RI.

FASE II: as situações de multiplicação dos professores B e C, reveladas na fase I, estão associadas aos objetivos 3 e 5 . Por suas justificativas convergirem para o objetivo 5 , foram identificadas como RI e RPC. As justificativas dos professores D e E estão associadas aos objetivos 4 e 1. Pelo fato das situações por eles referidas terem sido associadas aos objetivos 4 e 6 na fase I, são categorizadas como RPC e RI. As justificativas sobre a divisão, dos professores C e E, estão associadas aos objetivos 3 e 1, mas, por terem sido, na fase I, associadas aos objetivos 16 e 1, caracterizam-se como RI e RPC. As justificativas dos professires B e D, que, na fase I, associaram-se aos objetivos 6 e 5, como nessa fase convergiram para os objetivos 16 e 5 , tiveram as suas associações com as categorias RI e RPC.

\section{Análise em relação aos significados}

FASE I: na adição, as situações dos professores B, D e E associam-se ao significado de multiplicação comparativa (1), enquanto a do professor $C$ associa-se ao significado de proporcionalidade (2). Na divisão, as situações dos professores B e E foram associadas ao significado de proporcionalidade (2), enquanto a situação do professor $\mathrm{C}$ ao de configuração retangular (3) e a do professor D ao de combinatória (4). A ausência de associação entre esses significados e as suas justificativas nas situações apresentadas pelos Pefais sobre a multiplicação/divisão conduziram-nas à categoria NR.

FASE II: as explicitações dos Pefais sobre as justificativas quanto à multiplicação/divisão permanecem sem apresentar registro entre as justificativas e os significados correspondentes, trazidos na fase I. Por isso, todas as associações foram categorizadas como NR.

\section{Comentário sobre a análise em relação aos objetivos/significados}

No que se refere à multiplicação, identificou-se que os professores C e D evoluíram, passando da categoria RI, na fase I, para a categoria RPC, na fase II. No que diz respeito à divisão, observou-se não haver indício de evolução, uma vez que o professor D manteve-se na categoria RPC. Em relação aos significados a serem vivenciados nessas situações sobre o ensino de multiplicação/divisão, foi possível conceber que os Pefais não os têm explorado nas suas práticas. Enfim, fica claro que eles não conseguem vivenciar, nas suas práticas de sala de aula em relação à multiplicação/divisão, os dezesseis objetivos e os quatro significados dos PCNs (1997).

O relato dessa análise sobre as OFs aponta um frágil embasamento de ordem epistemológico-pedagógica acerca da adição, da multiplicação e das suas inversas. Não há o registro de nenhuma situação de ensino sobre a potenciação porque os docentes podem não reconhecê-la, o que abre espaço para a realização de pesquisas interessantes. De posse do reconhecimento desses déficits e dos registros que aludem ao conhecimento prévio desses Pefais acerca das OFs como resultado da pesquisa que originou este artigo se apresenta, em seguida, o texto de apoio produzido para ser vivenciado no ensino de raiz quadrada.

\section{O ENSINO DE RAIZ QUADRADA POR MEIO DO USO DA HM}


Esta pesquisa visa à elaboração de material de apoio potencialmente significativo para o ensino de raiz quadrada para professores e estudantes dos Aief. Esse texto de apoio apresenta duas situações: uma voltada para questões conceituais, de cunho epistemológico, explorando a noção de quadrados perfeitos em termos aritmético e geométrico; e outra para a obtenção da raiz de valores que não são quadrados perfeitos.

A proposta, inicialmente, procura despertar nos participantes o reconhecimento sobre a possibilidade de implicações favoráveis ao ensino da matemática com uso da HM. Ela possui três atividades: a primeira consiste em explorar alguns clássicos, como Davis e Hersh (1985), Boyer (2012), Ríbinikov (1991) e Cajori (2007), para evidenciar o valor pedagógico e o reconhecimento da HM como tendência em educação matemática. A ênfase da segunda atividade recai sobre o enfoque cognitivo análogo aos propósitos trazidos por Silva et al. (2017). Uma vez levantadas as concepções prévias dos professores, procura-se, na perspectiva da TAS, explorar semelhanças e diferenças entre objetos aritméticos e geométricos sobre a noção de quadrado perfeito, visando à aprendizagem significativa de raiz quadrada.

Parte-se do estudo exploratório que foi desenvolvido por Silva (2006), Aquisição do conceito de raiz quadrada: relato de uma experiência espontânea, que visa relacionar a ideia de raiz quadrada com a noção de quadrado perfeito. Para dar conta disso, apoia-se no conhecimento que a criança investigada possui sobre a operação de multiplicação e "tabuada", destacando, na operação de multiplicação de números inteiros, os produtos obtidos de fatores iguais:

$$
\begin{array}{lll}
2 \times 2=4 & 3 \times 3=9 & 4 \times 4=16 \\
5 \times 5=25 & 6 \times 6=36 & 7 \times 7=49
\end{array}
$$

Tenta-se fazer com que a criança compreenda que, ao dividir um número inteiro que tenha sido obtido como o resultado da multiplicação (produto) de fatores iguais por um desses fatores, a resposta será o mesmo fator, conforme apresentado. Como se observa, a proposta de Silva (2006) está mais voltada para o âmbito aritmético.

$\mathrm{Na}$ terceira atividade, procura-se algo que esteja mais relacionado com o enfoque geométrico. Em vez de formas pictóricas representadas por algarismos, recorre-se aos chamados números figurados ${ }^{3}$, que emergem do pressuposto de que "Todos os números, ou seres, teriam evoluído a partir do Um. Os números eram divididos em tipos associados aos diferentes tipos de coisas. Para cada tipo, havia um primeiro, ou menor número, considerado sua 'raiz'. [...]”' (ROQUE, 2012, p. 105).

Assim, quando os pontos estão dispostos como figuras que constituem um quadrado, têmse os números quadrados que, no caso deste estudo, se optou por indicar a raiz quadrada dos três quadrados perfeitos seguintes: 4, 9 e 16, devidamente representados abaixo.

Figura 4 - Representação dos números quadrados: $2^{2}, 3^{2}$ e $4^{2}$.

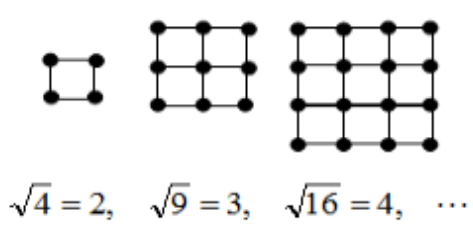

Fonte: Roque (2012, p. 106)

Ao término da terceira atividade, alude-se à potência, introduzida a partir da inter-relação entre a segunda e terceira atividades. Recorre-se aos produtos obtidos de fatores iguais na multiplicação, à noção de quadrados perfeitos e aos números figurados, explorando a forma de escrevê-los: $2^{2}=2 \times 2$

\footnotetext{
${ }^{3}$ Como esclarece Roque (2012), correspondem à representação de números em forma de figuras constituídas por pontos.
} Educação em Revista|Belo Horizonte|v.37|e25928|2021 
$=4,3^{2}=3 \times 3=9,4^{2}=4 \times 4=16$. Por fim, informa-se que o expoente que, indica o número de vezes de repetição do fator nesses três casos é dois e que o resultado do produto chama-se potência.

Em seguida, recomenda-se ampliar o repertório de quadrados perfeitos e questionar: como determinar a raiz quadrada de números inteiros que não possuam quadrados perfeitos, cujos fatores sejam diferentes? Nessa situação, utiliza-se a HM e, em particular, um procedimento desenvolvido pelos babilônios, cuja finalidade era, conhecendo-se a priori a área de um retângulo, obter um quadrado de área igual.

Esse processo é obtido por meio de aproximações das medidas distintas dos lados da forma retangular inicial até se chegar à medida do lado de um quadrado que tenha área igual à do retângulo dado. Para aludir a esse procedimento, recorreu-se a Barderas (2000, p. 196-197):
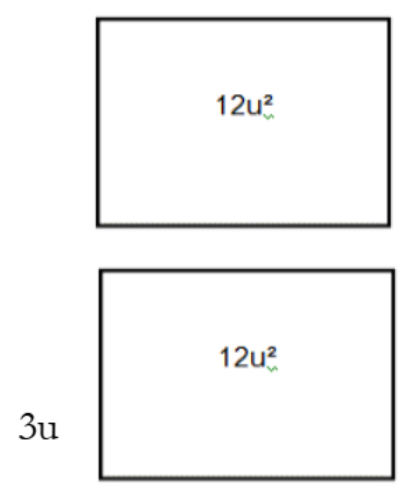

$4 \mathrm{u}$

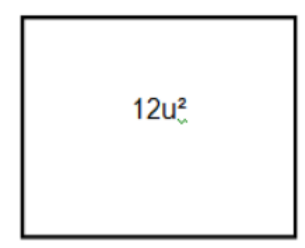

$3.4286 \mathrm{u}$
"Ejemplo.

Obtener la raíz cuadrada de $12(\sqrt{12})$.

1. Partamos de un rectángulo de $12 u^{2}$ de área.

2. Como la parte entera de $\sqrt{12}$ es $3, \frac{12 u^{2}}{3 u}=4 u$, el largo del rectángulo debe tener $4 \mathrm{u}$ y el ancho $3 u$.

3. Hagamos el promedio entre estas dos dimensiones:

$$
\frac{4 u+3 u}{2}=\frac{7 u}{2}=3.5 u
$$

Este nuevo valor de $3.5 \mathrm{u}$ debe ser el ancho de un nuevo rectángulo de $12 u^{2}$ de área, cuyo largo es:

$$
\frac{12 u^{2}}{3.5 u}=3.4286 u
$$

$[\ldots]$

5. Hagamos un tercer promedio entre las nuevas dimensiones:

$$
\frac{3.4643 u+3.4639 u}{2}=3.4641 u
$$

Este nuevo valor de $3.4641 \mathrm{u}$ debe ser el ancho de un nuevo rectángulo de $12 \mathrm{u}^{2}$ de área, cuyo largo es:

$$
\frac{12 u^{2}}{3.4641 u}=3.4641 u
$$

$3.4641 \mathrm{u}$

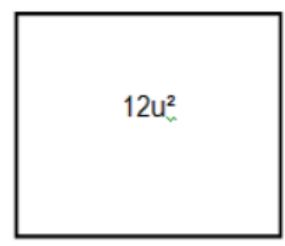

$3.4641 \mathrm{u}$

$[\cdots]$

En efecto, a guisa de comprobación con la calculadora, $\sqrt{12}=4641 \mathrm{u}$. Se pude apreciar, además, que éste es un procedimiento decuadratura". 
O relato dessa análise sobre as operações fundamentais, além de um frágil embasamento de ordem epistemológico-pedagógica acerca da adição, multiplicação e as suas inversas, como não enfoca o registro de nenhuma situação de ensino sobre a potenciação por esses Pefais, revela que eles podem não reconhecê-la como tal e abre espaço para a realização de pesquisas interessantes. Assim, de posse do reconhecimento desses déficits e dos registros que aludem ao conhecimento prévio desses Pefais acerca das operações fundamentais como resultado da pesquisa que originou este artigo, apresenta-se em seguida o texto de apoio produzido para ser vivenciado no ensino de raiz quadrada.

\section{CONSIDERAÇÕES FINAIS}

A análise dos propósitos educativos recomendados como objetivos nos PCNs (1997) em relação à adição/subtração e multiplicação/divisão permitiu reconhecer que os Pefais deste estudo precisam aprofundar as suas compreensões sobre as OFs. Para justificar esse argumento, basta lembrar que somente o professor D sobressaiu-se como melhor a demonstrar os conceitos na subtração, na multiplicação e na divisão, superando o seu próprio desempenho em relação à adição e os demais docentes, tanto na adição/subtração como na multiplicação/divisão. Além disso, o melhor desempenho do professor D surpreende por não acontecer também na adição, considerada a mais elementar das operações fundamentais.

Tomando-se como base os propósitos educativos indicados nos PCNs (1997), no que tange aos significados a serem vivenciados na adição/subtração e na multiplicação/divisão, considera-se que, apesar de as situações trazidas pelos Pefais possibilitarem associação com esses significados, não há, nos argumentos por eles apresentados, alusão a esses significados. A ausência de associações nas justificativas dos professores, nas suas tentativas de esclarecer a importância do uso das situações que utilizam nas suas aulas sobre OFs, deixa claro que, nesse contexto, eles não exploram os já referidos significados.

Os conhecimentos prévios dos Pefais revelaram ausência da potenciação/radiciação como OFs nas situações selecionadas, bem como nas justificativas esboçadas na tentativa de explicitar a importância do uso dessas situações em suas práticas. Esse comentário, aliado ao fato posto na introdução, a partir das publicações sobre os Aief, nas revistas Bolema, Zetetiké e Dynamis, evidencia a necessidade de pesquisas sobre OFs, inclusive para suprir essa ausência.

As alegações neste artigo têm o propósito de produzir um material educativo para o ensino de raiz quadrada nos Aief que esteja embasado na HM e na TAS, com intuito de que possa ser qualificado como um material potencialmente significativo do ponto de vista ausubeliano. A síntese de uma visão panorâmica acerca do material foi caracterizada no tópico "O ensino de raiz quadrada por meio do uso da HM", porém, a avaliação de tal potencialidade será tratada em outro artigo, analisando se nos mapas conceituais produzidos por esses Pefais há indícios de mudanças nas suas práticas sobre o ensino de raiz quadrada.

De modo abrangente, emergiu uma inquietação no mínimo interessante: trata-se do fato de que, ao serem indagados sobre o que fundamenta a organização das suas práticas, os Pefais se reportaram aos PCNs, à Base Curricular Comum do estado do Piauí e aos livros didáticos. No entanto, depois de mais de vinte anos da implementação dos PCNs, aqueles com uma média de 12 anos de magistério, conforme os resultados apresentados, revelam fragilidade sobre tal utilização nas suas práticas. Diante disso, torna-se oportuno questionar se a implementação da Base Nacional Comum Curricular oportuniza aos professores do ensino básico condições melhores que os PCNs para favorecer o desempenho organizacional das suas práticas docentes.

Vale apenas registrar que o propósito didático que envolve a abordagem educativa matemática do material leva em consideração a perspectiva do saber apontado por Chevallard (1991), as noções matemáticas, paramatemáticas e protomatemáticas. Além disso, impulsionado pelo desejo de compartilhar os pressupostos desse propósito didático sobre o ensino de potenciação, em particular a raiz quadrada, como conteúdo curricular a ser implementado nos Aief, recorreu-se ao mapa conceitual elaborado para esse fim, apresentado a seguir.

Figura 5 - Mapa Conceitual sobre a Operação de Potenciação. 


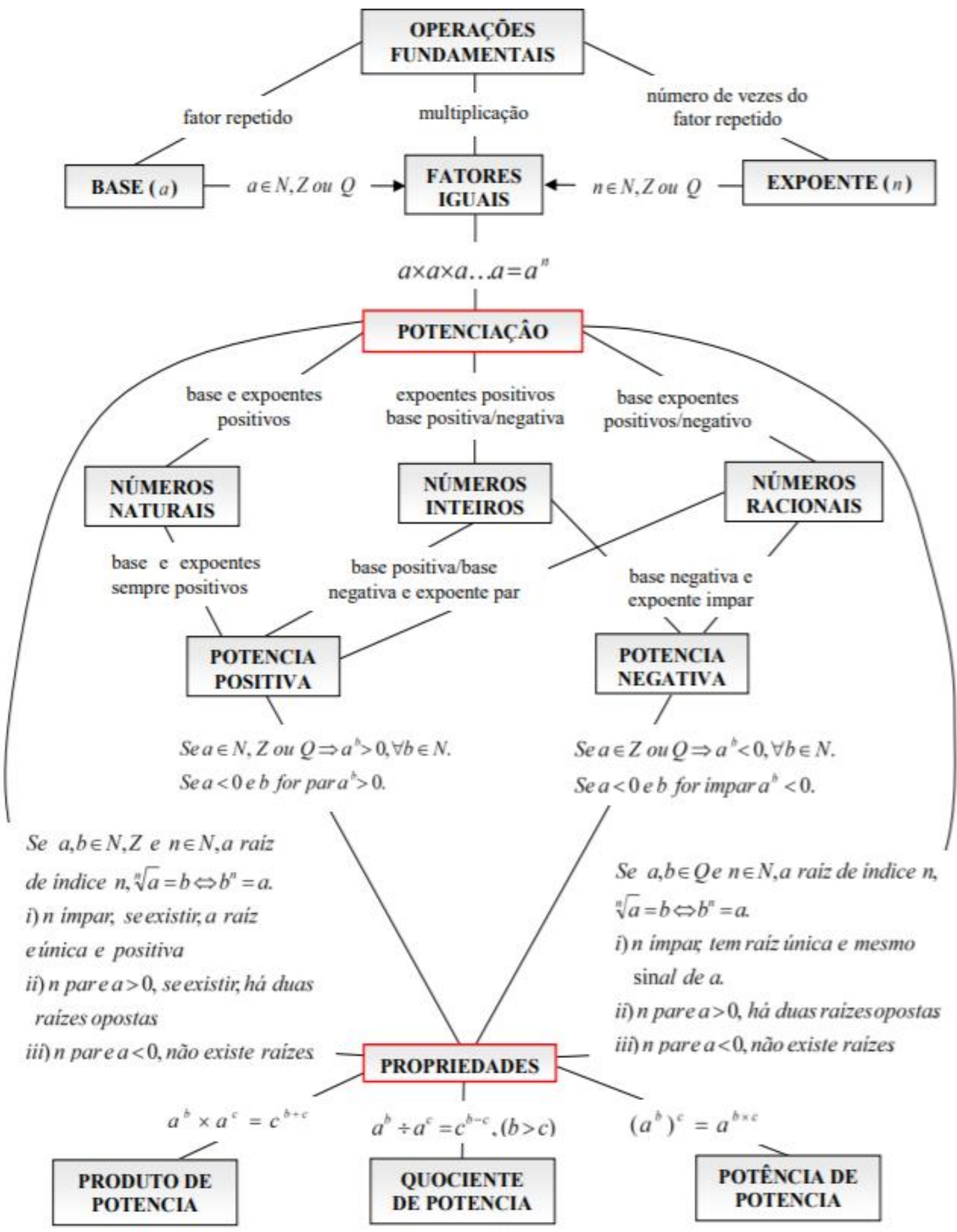

Fonte: elaborado pelo autor 2.

\section{REFERÊNCIAS}

ANDRÉ, Marli Eliza Dalmazo Afonso de. Etnografia da prática escolar. 18. ed. São Paulo: Papirus, 2011.

ARAMAN, Eliane Maria de Oliveira; BATISTA, Irinéa de Lourdes. Contribuições da História da Matemática para a Construção dos Saberes do Professor de Matemática. Bolema, v. 27, n. 45, p. 1-30, 2013. Disponível em: <https://www.scielo.br/ pdf/bolema/v27n45/v27n45a02.pdf>. Acesso em: 04/06/2019. 
AUSUBEL, David Paul. Adquisición y retención del conocimiento: Una perspectiva cognitiva. Barcelona: Padiós, 2002.

BARDERAS, Santiago Valiente. Didáctica de la Matemática -El libro de los recursos. Madrid: La Muralla, 2000.

BIGODE, Antonio José Lopes. Matemática do cotidiano e suas conexões. 1. ed. São Paulo: FTD, 2005.

BONJORNO, José Roberto.; AZENHA, Regina; GUSMÃO, Tânia. Matemática. $5^{\circ}$ Ano: Girassol saberes e fazeres do campo. São Paulo: FTD, 2014.

Boyer, Carl Benjamin. História da Matemática. 2. ed. São Paulo: Edgard Blücher, 1996.

Boyer, Carl Benjamin. História da Matemática. 3. ed. São Paulo: Editora Edgard Blucher, 2012.

BRASIL. Secretaria de Educação Fundamental. Parâmetros curriculares nacionais: matemática. Brasília: $\mathrm{MEC} / \mathrm{SEF}, 1997$.

CAJORI, Florian. Uma história da Matemática. Rio de Janeiro: Editora Ciências Moderna, 2007.

CARVALHO, João Bosco Pitombeira de. (2010). A raiz quadrada ao longo dos séculos. In: BIENAL DA SOCIEDADE BRASILEIRA DE MATEMÁTICA, 5., 2010, João Pessoa. Anais [...]. Joao Pessoa: V Bienal da SBM, 18 a 22 de out. 2010. Disponível em:

$<$ http://www.mat.ufpb.br/bienalsbm/arquivos/mais_trabalhos/MC11.pdf>. Acesso em: 30/03/2020.

CHEVALLARD, Yves. La transposición didáctica: Del saber sabio al saber enseñado. Tradução de Claudia Gilman. Editora Aique: Buenos Aires, 1991.

DAMAZIO, Ademir. O Processo de Elaboração do Conceito de Potenciação de Números Fracionários: uma abordagem histórico-cultural. Bolema, v. 24, n. 38, p. 219-243, 2011.

DAVIS, Philip. \& HERSH, Reuben. A Experiência Matemática. Rio de Janeiro: F. Alves, 1985.

DESLAURIERS, Jean Pierre. Recherchequalitative: guide pratique. Québec (Ca): McGrawHill Éditeurs, 1991.

DIONNE, Hugues. A pesquisa-ação para o desenvolvimento local. Tradução de Michel Thiollent. Brasilia: Líber Livro Editora, 2007.

ELIOTT, John. El cambio educativo desde la investigación-acción. Madrid: Morata, 1993.

GERHARDT, Tatiana Engel; SILVEIRA, Denise Tolfo. Métodos de pesquisa. Porto Alegre: Editora da UFRGS, 2009.

GOMES, Thiago de Azevedo; RODRIGUES, Chang Kuo. A evolução das tendências da educação matemática e o enfoque da história da matemática no Ensino. Revista de Educação, Ciências e Matemática, v. 4, n. 3, p. 57-67, 2014. Disponível em:

<http://publicacoes.unigranrio.edu.br/index.php/recm/article/view/2687/1264.>.

Acesso em: 18/07/2018.

GONÇALVES, Ida Maria Faria de Lira. Os Problemas da Matemática: o seu papel na Matemática e nas aulas de Matemática. 2011. 473f. Tese (Doutorado em Matemática - Ensino de Matemática) - 
Universidade da Madeira, Funchal - Portugal, 2011. Disponível em:

$<$ https://digituma.uma.pt/bitstream/10400.13/559/1/ DoutoramentoIdaGoncalves.pdf $>$. Acesso em: 12/08/2018.

MENDES, Iran Abreu.; CHAQUIAM, Miguel. História nas aulas de Matemática: fundamentos e sugestões didáticas para professores. Belém: SBHMat, 2016.

MENDES, Iran Abreu.; FOSSA, John Andrew; VALDÉS, Juan Nápolis. A bistória com um agente de cognição na educação matemática. Porto Alegre: Sulina, 2006.

MOL, Rogério Santos. Introdução à história da matemática. Belo Horizonte: CAED-UFMG, 2013.

MORAES, José Uibson Pereira. Representação do processo de Assimilação e Retenção do conhecimento de Ausubel. In: CONGRESSO NORTE NORDESTE DE PESQUISA E INOVAÇÃO, 7., 2012, Palmas. Anais [...]. Palmas: VII CONNEPI, 19 a 21 de out. 2012._Disponível em: <http://propi.ifto.edu.br/ocs/index.php/ connepi/vii/paper/view/2124/2255>. Acesso em: 01/07/2019.

MOREIRA, Marco Antonio. Aprendizagem Significativa: a teoria e textos complementares. São Paulo: Editora Livraria da Física, 2011a.

MOREIRA, Marco Antonio. Metodologias de pesquisa em ensino. São Paulo: Editora Livraria da Física, $2011 b$.

MOREIRA, Marco Antonio. Subsidios teóricos para o professor pesquisador em ensino de ciências: A Teoria da Aprendizagem Significativa. 2. ed. revisada. Porto Alegre, RS, 2016. Disponível em: < https://www.if. ufrgs.br/ $\sim$ moreira/Subsidios6.pdf $>$. Acesso em: 23/05/2019.

NISS, Morgens. O projeto dinamarquês KOM e suas relações com a formação de professores. In: M. C. Borba (org.). Tendências internacionais em formação de professores de matemática. 2. ed. Belo Horizonte: Autêntica Editora, 2010. p. 27-44.

PEREIRA, Rúbia Carla; PAIVA, Maria Auxiliadora Vilela; FREITAS, Rony Cláudio Oliveira. A transposição didática na perspectiva do saber e da formação do professor de matemática. Educ. Matem. Pesq., v.20, n.1, p. 041-060, 2018.

POZO, Juan Ignacio. Teorias cognitivas da aprendizagem. 5. ed. São Paulo: Artes Médicas, 2005.

RÍBNIKOV, Konstantin. Historia de las Matemática. Madrid: Librería Rubiños, 1991.

RÍBNIKOV, Konstantin. História de las Matemáticas. Moscú: Editorial Mir, 1987.

ROQUE, Tatiana. História da matemática: Uma visão crítica, desfazendo mitos e lendas. Rio de Janeiro: Zahar, 2012.

SAMPIERI, Roberto Hernández.; COLLADO, Carlos Fernández; LUCIO, Pilar Baptista. Metodología de la Investigación. 5. ed. México: McGraw-Hill, 2010.

SILVA, José Roberto da. Uma abordagem Ausubeliana da Aquisição do Conceito de Raiz Quadrada Contextualizada Segundo a Teoria de Lakoff. In: Recursos Didáticos: Textos de Apoio para

o Ensino de Ciências e Matemáticas. Recife: EDUPE, 2006.p. 15-36. 
SILVA, José Roberto da. Textos de apoyo como organizadores previos para la enseñanza de Álgebra, Combinatoria, Lógica Matemática y Geometría Euclidiana. 2009. Tese (Doutorado em Enseñanza de las Ciencias).

Universidade de Burgos, UBU, Espanha, 2009.

SILVA, José Roberto da. et al. Ensino De Raiz Quadrada: Elaboração de um Organizador Prévio. In: ENCONTRO PERNAMBUCANO DE EDUCAÇÃO MATEMÁTICA, 2017. Anais eletrônicos [...] Garanhuns-PE, 2017. Disponível em:

$<$ http://epem.sbempe.com.br/anais/2017/index_menu.html?page=publications\&subpage=RE\&l anguage $=$ br $>$. Acesso em: 02/12/2017.

UJIIE, Nájela Tavares. et al. Os conhecimentos prévios de matemática de estudantes do ensino fundamental: o que é matemática? De onde ela veio? Como seria um mundo sem matemática? ALEXANDRLA: Revista de Educação em Ciência e Tecnologia, v. 10, n. 1, p. 57-73, 2017. Disponível em: https://periodicos.ufsc.br/index.php/ alexandria/article/view/1982-5153.2017v10n1p57. Acesso em:

VIGOTSKI, Lev Semionovitch. A Construção do Pensamento e da Linguagem. São Paulo: Marins Fontes, 2001.

Submetido: $20 / 10 / 2020$

Aprovado: 14/06/2021 